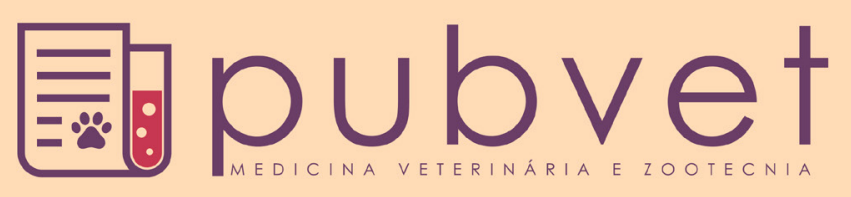

HTTP://DX.DOI.ORG/10.22256/PUBVET.V11N4.381-392

\title{
Manejo do complexo respiratório bovino em confinamento: Revisão
}

\author{
Diego Slompo*1, Heloisa Godoi Bertagnon², Egon Henrique Horst ${ }^{3}$, Mikael Neumann², \\ Juliana Mareze ${ }^{3}$, André Martins de Souza ${ }^{1}$, Edelmir Silvio Stadler Júnior ${ }^{1}$, Iara Goldoni ${ }^{1}$, \\ Eloize Jaqueline Askel ${ }^{1}$
}

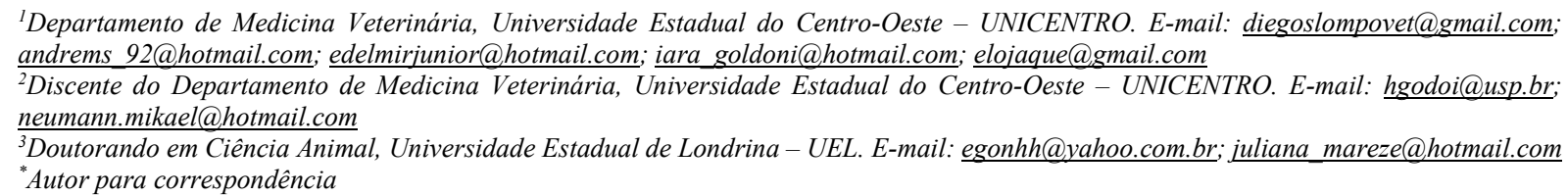

RESUMO. O complexo respiratório bovino, também conhecido como a febre do transporte, é de grande importância econômica para a indústria pecuária de todo o mundo. O controle da doença é complicado devido a essa enfermidade ter caráter multifatorial. Diferentes combinações de fatores como associação de microrganismos patogênicos, condições ambientais estressantes e animais imunologicamente susceptíveis, podem acarretar a doença e perpetuá-la no rebanho.

Palavras chave: doença respiratória bovina, febre do transporte, imunoprofilaxia

\section{Management of Bovine Respiratory Complex in Feedlot: Review}

ABSTRACT. The bovine respiratory complex, also known as the transport fever, is of great economic importance to the livestock industry around the world. The control of the disease is complicated because this disease has a multifactorial character. Different combinations of factors such as the association of pathogenic microorganisms, stressful environmental conditions and immunologically susceptible animals can lead to disease and perpetuate it in the herd.

Keywords: Bovine respiratory disease, transport fever, immunoprophylaxis

\section{Manejo del complejo respiratorio bovino en corral de engorde: Revisión}

RESUMEN. El complejo respiratorio bovino, también conocido como la fiebre del transporte, es de gran importancia económica para la industria ganadera en todo el mundo. El control de la enfermedad es complicado por causa de la enfermedad tener carácter multifactorial. Las diferentes combinaciones de factores tales como la asociación de microorganismos patógenos, condiciones ambientales estresantes y animales inmunológicamente susceptibles pueden conducir a la enfermedad y perpetuarlo en el rebaño.

Palabras clave: enfermedad respiratoria bovina, fiebre del transporte, inmunoprofilaxis

\section{Introdução}

As doenças infecciosas em ruminantes, tais como o complexo respiratório bovino (CRB), são conhecidas por terem um significativo impacto econômico negativo na pecuária intensiva tanto de corte quanto de leite no tocante aos custos de 
tratamento, prejuízos no desempenho e bem-estar dos animais de todo o mundo, sendo considerado o maior problema de confinamento nos Estados Unidos e Austrália perda econômica e o difícil controle da doença ( Snowder et al., 2006, Hay et al., 2016b).

O Complexo respiratório bovino é o principal causador de doença clínica e morte em bovinos confinados. O controle da doença é complicado devido a essa enfermidade ter caráter multifatorial. Diferentes combinações de fatores como associação de microorganismos patogênicos, condições ambientais estressantes e animais imunologicamente susceptíveis, podem acarretar a doença e perpetuá-la no rebanho, uma vez que a transmissão ocorre por contato direto, aerossol e exposição à fômites contaminados nos currais snowder (Snowder et al., 2006). Com isso, a percepção dos fatores de risco aliado a ações precoces no manejo do gado faz-se necessária para que a incidência da afecção seja mínima e não onerosa, preferindo-se medidas de controle, que muitas vezes, não são efetivas apenas com tratamentos medicamentosos.

A utilização de vacinas atenuadas, medicação em massa com antibióticos de última geração, tanto para profilaxia quanto metafilaxia, e também a utilização do manejo todos dentro/todos fora, não são o suficiente para controlar este grave problema chamado CRB. Não obstante, o reconhecimento precoce da CRB é essencial para a prevenção da mesma, associado ao controle dos fatores de risco, pois por meio disto sabe-se efetivamente se as medidas adotadas no manejo tiveram êxito ou não. $\mathrm{O}$ tratamento é de grande interesse para promover o bom estado de saúde e a retoma de ganhos produtivos pelos animais. Porém, os sinais clínicos muitas vezes aparecem tardiamente, e isso, a nível produtivo, pode ser decisivo no lucro perante a unidade animal.

Vários métodos diagnósticos podem ser usados, porém, vários são invasivos e exigem a contenção e manipulação dos animais em troncos, aumentando o estresse nos animais.

Essa revisão de literatura tem como objetivo abordar, de forma geral, o Complexo Respiratório Bovino nos confinamentos.

\section{Complexo respiratório bovino: CRB}

O complexo respiratório bovino, também conhecido como a febre do transporte, é de grande importância econômica para a indústria pecuária de todo o mundo. Os Estados Unidos da América estimam uma perda anual com a afecção de aproximadamente U\$ 1 bilhão, devido à queda produtiva, aumento de despesas com manejo, custos com medicamentos e morte dos animais (Hay et al., 2016a).

\section{Patogênese e etiologia}

O estresse, agentes virais ou parasitários geram uma imunussupressão no hospedeiro, permitindo assim que essas bactérias comensais de bovinos tornem-se oportunistas e multipliquem-se rapidamente no trato respiratório superior. As principais bacterias envolvidas são Pasteurella multocida, Mannhemia haemolytica, Histophilus somni, Mycoplasma bovis (Edwards, 2010).

O sistema de comercialização e manejo alimentar do gado provoca estresse inerente nos animais, pois a maioria dos bezerros são desmamados e transportados para um local específico em conjunto com outros bovinos, dos quais pouco se sabe sobre a sanidade ou situação vacinal. Bezerros que atravessam longas distâncias são expostos a fatores estressantes como a inalação de fumaça de óleo diesel, desafios térmicos extremos e até mesmo desidratação, fome e exaustão (Rice et al., 2007).

Após o transporte, fatores adicionais geram ainda mais estresse aos recém-chegados, pois uma nova rotina apossa-se de sua existência. O desafio alimentar para um ótimo desempenho, o ambiente empoeirado, água diferente a que estavam acostumados, formação de lotes de bezerros de origens distintas, entre outras mudanças radicais sofridas, torna-se assim o animal ainda mais susceptível ao contágio da CRB (Srikumaran et al., 2007, Rice et al., 2007).

Frank (1984) cita que a primeira linha de defesa é o epitélio da mucosa respiratória, que detém barreiras químicas, microbiológicas e mecânicas para impedir a entrada de patógenos. No entanto algumas bactérias podem ser inaladas em conjunto com gotículas de água, e colonizara traqueia. Essa, por sua vez, possui epitélio que libera secreção que reveste o mesmo, dificultando a aderência bacteriana. Além disso, as células ciliares tem o papel de expelir esse muco através de movimentos ascendentes, chamado de depuração mucociliar (Lillie and Thomson, 1972). Uma pequena porção de patógenos que conseguir ultrapassar estas barreiras chegam ao pulmão, cujo epitélio é revestido com proteínas tensoativas A e D e também defensina, que são capazes de facilitar a fagocitose por macrófagos e neutrófilos, a 
primeira linha de defesa imune inata.

Lesões no trato respiratório podem ser prejudicadas por uma coinfecção por vírus, pois esses prejudicam a depuração mucuciliar normal do animal. Um exemplo é o vírus da Diarreia Viral Bovina (BVD), pois sua replicação prejudica ou destrói os macrófagos alveolares e também danificam as células ciliares presentes na traquéia, que impedem sua ação efetiva, gerando no animal uma imunosupressão.

A virulência causada pelo Vírus Sincicial Respiratório Bovino (BRSV) depende da idade e do estado imunológico do hospedeiro, sendo a maioria dos bovinos assintomáticos. A primeira infecção em células epiteliais da cavidade nasal, faringe, traqueia, brônquios e de bronquíolos induz a necrose e a perda das células mucociliares. Com isso, ocorre acúmulo de detritos e do muco propriamente dito, proporcionando um exelente meio de cultura nas vias aéreas para as bactérias. A BRSV também deprimem a fagocitose e a opsonização por macrófagos alveolares. $\mathrm{O}$ vírus Herpes Bovino tipo 1 (BHV-1) se replica primeiramente nas células do trato respiratório superior e posteriormente no inferior, causando efeitos semelhantes ao BRSV além de exacerbar a infecção bacteriana secundária devido as lesões causadas (Griffin et al., 2010).

$\mathrm{O}$ vírus da Parainfluenza Tipo 3 (PI-3) é quase sempre assintomático para bovinos, porém predispõe infecções bacterianas secudárias no parênquima pulmonar devido à limitada depuração e expulsão mucociliar de líquido, poeira, detritos celulares e demais estruturas pelas vias aéreas, ou seja, o aparecimento do CRB depende principalmente de um fator estressante com uma coinfecção viral ou bacteriana. Esses fatores, individualmente ou em combinação, podem proporcionar uma infecção bacteriana persistente devido a uma resposta imune inata ineficiente (Srikumaran et al., 2007).

\section{Mannheimia haemolytica}

Bactéria gram-negativa, anaeróbia facultativa, hemolítica positiva em ágar sangue, oxidase positiva, sem motilidade, que possui capacidade de fermentação e não é formadora de esporos. Pertence ao gênero Mannheimia que, por sua vez, faz parte da classe $\alpha$-Proteobacteria, ordem Pasteurellales e família Pasteurellaceae. Esta bactéria é dividida em 12 sorotipos capsulares (Griffin et al., 2010).

$\mathrm{O}$ agente bacteriano está presente na flora normal do trato respiratório superior de ruminantes hígidos. Esta relação permanece comensal até que o hospedeiro sofra algum fator estressante ou uma coinfecção. A partir de então, a bactéria torna-se oportunista, proporcionando assim uma broncopneumonia fibrinosa característica pela multiplicação predominante do sorotipo A1 (Griffin et al., 2010).

Sua importância advém dos fatores de virulência responsáveis pela gravidade da doença. Entre eles, cita-se a presença de uma cápsula capaz de se aderir e invadir os pneumócitos, como também, a presença de proteínas na membrana externa, que são produtoras de respostas imunológicas protetoras (adesina, neuraminidases, lipopolissacarídeos e leucotoxinas). A adesina é utilizada para a colonização. As neuraminidases são responsáveis pela redução da viscosidade do muco respiratório, abrindo passagem para a entrada das bactérias no parênquima das vias respiratórias. Os lipopolissacarídeos irão gerar hemorragia, edema, hipóxia e inflamação aguda e as leucotoxinas são responsáveis pela lise dos leucócitos dos bovinos, sendo esta última, o principal fator de virulência (Rice et al., 2007).

\section{Pasteurella multocida}

Esta bactéria possui cinco sorogrupos (A-F) e 16 sorotipos (1-16) (Boyce and Adler, 2000, Dabo et al., 2007). A versão mais encontrada e isolada no CRB é a A:3 (Boyce and Adler, 2000).

A P. multocida comumente é identificada em animais jovens portadores de síndromes como a pneumonia enzoótica neonatal de bezerros e a febre do transporte após desmame, que é gerado um alto estresse ao animal (Apley, 2006). No entanto, fatores predisponentes adicionais que reduzem a imunidade do animal são necessários para que ocorra a pneumonia associada a $P$. multocida, como climas desafiadores, condições ambientais desfavoráveis, nutrição adversa (alimentos danificados e adaptações de dietas mal feitas), manejo incorreto dos animais, transporte e também a interação de outros patógenos listados anteriormente causadores do complexo, assim como comorbidades gastrointestinais e parasitarias (Boyce and Adler, 2000).

O isolamento desta bactéria é facilmente realizado a partir de secreção nasal de bezerros jovens recém-desmamados. Em bezerros sadios, a presença desse agente está entre $20-60 \%$ (Dabo et al., 2007). Essa alta taxa de isolamento permite 
afirmar que a bactéria é comensal do trato respiratório superior dos bovinos, e para correlacionar esta bactéria como o agente causal do $\mathrm{CRB}$, é necessário mais que o dobro do isolamento em comparado com animais sem sinais clínicos (Carroll and Forsberg, 2007, Dabo et al., 2007).

Prado et al. (2006) defendem que a $P$. multocida é considerada o principal agente causal do óbito dos animais em confinamento. Possivelmente a intensificação da produção de carne levou a animais que entram em confinamentos cada vez mais jovens, e a sofrerem aos desafios estressantes mais precocemente, o que favorece a colonização pulmonar por esta bactéria, contrariando pesquisas anteriores que defendiam que sumariamente a $M$. haemolytica era a responsável pelos casos fatais (Snowder et al., 2006, Rice et al., 2007).

\section{Histophilus somni}

É uma bactéria gram-negativa encontrada em bovinos confinados e é considerada comensal da região da nasofaringe, podendo preferencialmente colonizar o trato respiratório inferior (Apley, 2006). A taxa de isolamento em lotes de bovinos clinicamente normais pode ser de $15 \%$ até $50 \%$ em bezerros recém-chegados demonstrando sinais clínicos de CRB (Booker et al., 1999, Apley, 2006).

As principais proteínas de membrana externa e fatores de virulência são semelhantes à Mannheimia haemolytica, mas também histamina e um exopolissacarídeo são produzidos a fim de desempenhar um papel na patogênese. Elas possuem atividade citotóxica, em especial para células endoteliais, responsáveis pela permeabilidade, permitindo assim que o patógeno se propague via hematógena por todo o sistema vascular do animal e também ela pode causar diversas doenças, tanto respiratórias como em formas isoladas no sistema cardíaco, septicemias, infecções reprodutivas, abortamentos e meningoencefalite tromboembólica (Griffin et al., 2010).

Clinicamente, a pneumonia causada por essa bactéria é indistinguível perante a mesma doença causada por outros agentes bacterianos no CRB já discutidos anteriormente (Apley, 2006). No exame macroscópico dos pulmões afetados, a observação mais comum é a extensa deposição de fibrina semelhante às lesões geradas por Mannheimia haemolytica e P. multocida, tornando assim o diagnóstico incerto frente aos três agentes etiológicos quando basea-se apenas em lesões macroscópicas (Griffin et al., 2010).

\section{Mycoplasma bovis}

O papel do Mycoplasma bovis em bezerros é mais bem compreendido do que em outras categorias animais (Griffin et al., 2010). Dados que definem a sua relação no $\mathrm{CRB}$ não são tão claros como ocorrem para os três patógenos bacterianos mencionados anteriormente (Apley, 2006). A utilização de swabs nasais não é tão eficiente uma vez que estas se encontram frequentemente em regiões mais profundas do trato respiratório. Sorologia usando ensaios imunoenzimáticos (ELISA) é utilizada para identificar a presença do agente. A reação em cadeia pela polimerase (PCR) pode ser utilizada para confirmar a presença da bactéria (Griffin et al., 2010). Essas técnicas são utilizadas para ajudar a elucidar a epidemiologia desse patógeno. A incidência varia entre os rebanhos, podendo ser praticamente zero até altas taxa de até $90 \%$. A resistência do animal ao agente é hereditária e dependente da carga bacteriana presente na lactante, pois o contagio pode se dar de forma horizontal, pelo agente presente na superfície da glândula mamária, que contamina o leite, que é passível de ser aspirado pelo bezerro. Essa última via torna-se a mais significante para a entrada do Mycoplasma bovis no trato respiratório. Uma vez estabelecido no animal, o agente pode coexistir com o mesmo durante toda vida.

\section{Herpesvirus bovino tipo 1}

O BHV-1 (Bovine herpesvirus 1) é o agente etiológico responsável pela IBR (rinotraqueíte infeciosa dos bovinos) que se replica em células da mucosa, submucosa e anéis traqueais (Hay et al., 2016b). Sinais e lesões são variáveis, podendo ser serosas, hiperêmicas, com edema e exsudato mucopurulento, necrose focal e em casos mais graves, inflamação pseudomembranosa (Cusack et al., 2003). Essas lesões irão possivelmente gerar destruição do epitélio do trato respiratório superior, o que diminui consideravelmente a atividade mucociliar, favorecendo uma broncopneumonia secundária devido à multiplicação bacteriana no pulmão, também prejudica os mecanismos de defesa pulmonar reduzindo migração de neutrófilos, resposta mitogênica linfocitária vascular periférica e atividades funcionais de macrófagos alveolares (Cusack et al., 2003). 


\section{Parainfluenza vírus tipo 3}

O PI-3 (Parainfluenza tipo 3) se replica nas células epiteliais de ambos os tratos respiratórios, porém o dano principal ocorre no inferior. Essa replicação irá provocar bronquite, bronquiolite e alveolite. Na fase aguda da infecção, ocorre proliferação e necrose de células epiteliais bronquiais com destruição generalizada dos cílios e de células ciliadas em pequenos brônquios e bronquíolos, então, o vírus infecta macrófagos alveolares possibilitando a ineficiência da resposta imune inata pulmonar, tornando os animais passíveis de contrair uma infecção bacteriana secundária (Cusack et al., 2003).

\section{Virus da diarreia viral bovina}

O papel da BVD (Bovine Viral Diarrhea) na patogênese do CRB é certo como doença primária e pode facilitar a colonização de agentes patogênicos nos pulmões, cuja maior exposição ao vírus demonstra maior risco da infecção no complexo respiratório em confinamentos (Hay et al., 2016a). Hay et al. (2016b) demonstraram em um estudo que animais não vacinados para BVD têm $\mathrm{o}$ risco de desenvolver problemas respiratórios multifatoriais aumentados.

$O$ efeito imunossupressor da BVD aguda parece ser mediado por hiperplasia inicial dos órgãos linfoides dentro de dez dias após a infecção, seguido por depleção linfoide (Baule et al., 2001). Além disso, a BVD prejudica a produção de anticorpos humorais, deprime a quimiotaxia de monócitos e prejudica o sistema mieloperoxidase antibacteriana em leucócitos polimorfonucleares (Roth et al., 1981). Presumivelmente, esses mecanismos favorecem a colonização dos pulmões por outros agentes patogênicos, que podem exacerbar a doença pulmonar que eles geram (Baule et al., 2001). O vírus da BVD também tem efeitos citopáticos diretos, que podem resultam em inflamação aguda catarral na cavidade nasal e traqueia e pneumonia intersticial focal intralobular, podendo este agente ser primário ou favorecer e agravar pneumonias causadas por outros agentes. (Baule et al., 2001).

\section{Virus sincicial respiratório bovino}

Este patógeno causa infecção pelo BRSV (vírus sincicial respiratório bovino) resulta na destruição do epitélio ciliado do trato respiratório e a baixa efetividade dos macrófagos alveolares comprometidos leva a uma depressão do sistema imune celular local. Essa interferência com a depuração pulmonar predispõe aos animais para uma infecção bacteriana secundária (Hay et al., 2016a). O envolvimento de BRSV em surtos de CRB clínico tem sido relatado na Europa e na América do Norte (Baker and Frey, 1985) e Austrália (Hay et al., 2016a).

\section{Fatores predisponentes para complexo respiratório bovino}

Os agentes virais podem causar danos diretos aos mecanismos de depuração respiratória e ao parênquima pulmonar além de interferir com a capacidade do sistema imunitário para responder a uma infecção bacteriana facilitando a translocação de bactérias a partir do trato respiratório superior e o estabelecimento da infecção pulmonar (Martin and Bohac, 1986).

O transporte é o fator de risco não infeccioso mais aceito para a afecção, que levou ao nome de febre do transporte, motivando inumeras pesquisas que relacionam distância e o tempo do transporte. O método de transporte também parece interferir, uma vez que quando há maior ventilação, como em tranportes realizados por trens, há menor incidência da doença em comparação com transporte em carretas de dois andares (Taylor et al., 2010). A desidratação também é uma das sequelas mais encontradas em animais transportados e tem sido sugerida como um mecanismo que impacta no complexo respiratório bovino (Taylor et al., 2010).

$\mathrm{O}$ aglomerado de bezerros de diferentes origens também aumenta os riscos da transmissão do complexo (Step et al., 2008), devido a maior exposição a patógenos, estresse durante múltiplos episódios de transporte e exposição a fungos (Radostits et al., 2002).

O clima tem sido observado no $\mathrm{CRB}$, pois a maior ocorrência quando a temperatura baixa. $\mathrm{O}$ outono é o momento tradicional para a comercialização de bovinos na América do Norte, resultando em um maior risco dos bezerros confinados nessa época do ano. Uma densidade de animais mais elevada predispõe a um maior risco de transmissão de micro-organismos, além de possibilitar maior estresse aos animais devido a aglomerações, ocorrência de doenças fúngicas e concorrência na alimentação e nos cochos de água (Taylor et al., 2010). Muitos autores sugerem que súbitas e abruptas mudanças climáticas predispõem o CRB nos rebanhos (Cusack et al., $\underline{2007)}$. Outras variedades investigadas foram umidade relativa do ar, velocidade do vento e 
precipitação de chuvas não possuindo nenhuma influência com a doença (Cusack et al., 2007).

Townsend et al. (1989) também relataram que a idade é um fator predisponente. Eles constataram que um bezerro mais novo tem cinco vezes mais chance de contrair a doença do que bezerros com uma diferença de idade de 100 dias. Outros autores também sugeriram que bezerros mais leves tem maior chance de adquirir a doença do que bezerros mais pesados (Bateman et al., 1990, Sanderson et al., 2008). Sanderson et al. (2008) determinaram que animais jovens com peso abaixo da média (< $250 \mathrm{~kg}$ ) são 1,4 vezes mais propensos de serem acometidos do que vitelos que possuem a média de peso acima da normal (>350 kg).

Em relação ao sexo dos animais, há estudos demonstrando queo bezerros machos possuiam mais chances de desenvolver a doença do que as bezerras tanto quando nasciam na propriedade (Wittum and Perino, 1995). Embora a herdabilidade da resistência a doença seja baixa, diferenças entre raças foram detectadas (Snowder et al., 2005), notando-se que animais Bos taurus são mais susceptíveis a afecção que da espécie $B o s$ indicus (Cusack et al., 2007), especialmente Angus e Hereford (Taylor et al., 2010). Por isso o cruzamento entre raças aumenta o vigor híbrido, sendo benéfico para a redução da doença respiratória (Snowder et al., 2005).

Vacas que têm sua primeira cria possuem níveis mais baixos de anticorpos no colostro, assim, seus bezerros são mais susceptíveis ao desenvolvimento da doença após o desmame, quando ainda fossem jovens, porém as matrizes com maior resistência proporcionariam uma imunidade passiva mais duradoura, transferida pela mãe foi ainda reforçada por um estudo que descobriu que a vacinação para BHV-1 e BVDV antes do parto diminuiu a incidência de bezerros com CRB após o desmame (Ganaba et al., 1995).

\section{Diagnóstico do complexo respiratório bovino}

A detecção precoce da doença é de extrema importância em bovinos confinados para evitar a transmissibilidade dentro do rebanho. No entanto, a detecção baseada apenas na inspeção dos sinais clínicos requer habilidade e experiência do responsável, tendo em vista que, os ruminantes são gregários na natureza e tendem a mascarar ou ocultar os sinais clínicos (Edwards, 2010).

Wittum et al. (1996) verificaram que $68 \%$ dos animais considerados sadios por meio de inspeção, apresentavam lesões pulmonares na hora do abate e que estas lesões pulmonares, em animais tratados ou não, causaram redução de aproximadamente $80 \mathrm{~g}$ do ganho médio diário de peso (GMD) por cabeça. Isso permite afirmar que a detecção visual do CRB não é precisa e tão pouco acurada, trazendo assim ao pecuarista prejuízos na produção e gastos inúteis com animais acometidos por outras doenças (Wittum et al., 1996).

Os principais sinais clínicos característicos são: depressão, anorexia, tosse, taquipneia, dispneia, sons respiratórios anormais, febre, rinorreia, narinas secas, corrimento ocular, orelha caída, magreza, pelagem seca e morte súbita (Duff and Galyean, 2007, Edwards, 2010). A febre, embora não seja específica para a doença, tem sido fortemente associada à doença após o agrupamento de bezerros em currais (Timsit et al., $\underline{2011 b}$ ). A auscultação pulmonar é uma ferramenta para a avaliação da qualidade dos sons pulmonares, assim como a percussão. Com este método é possível determinar o grau de desenvolvimento e a natureza da lesão, assim como delimitar o tecido pulmonar acometido (Radostits et al., 2002). Quanto à percussão da região pulmonar, segundo Flöck (2004) pode ocorrer um aumento ou diminuição da ressonância, quando maciça se trata de enfisema pulmonar ou de pleurite e efusão pleural.

A história clínica é de extrema importância, pois permite ao médico veterinário estabelecer uma gama de diagnósticos diferenciais possíveis. Com isto, o clínico pode selecionar os meios de diagnósticos mais apropriados respeitando $\mathrm{o}$ aspecto econômico sobre o sistema produtivo abordado, sugerir outros testes ou seleção de amostras e avaliar se correspondem ao problema do grupo. A informação inerente a todos os animais, saudável ou não, pode fornecer dados sobre possíveis fatores de risco, assim como detectar deficiências de manejo que podem predispor os animais ao CRB (Cooper and Brodersen, 2010). É necessário utilizar exames complementares para detectar precocemente a doença. Atualmente, apesar de existirem inúmeros métodos de diagnósticos, ainda não existe um com elevada precisão e acurácia para o CRB que possa ser utilizado em confinamentos (Duff and Galyean, 2007).

Os testes laboratoriais frequentemente utilizados incluem sorologia, isolamento viral e bacteriano, microscopia eletrônica, imunofluorescência, imunohistoquímica e PCR 
(Fulton and Confer, 2012). No entanto, além da sua utilidade estar limitada pela demora na obtenção dos resultados, por serem onerosos, necessitam da contenção dos animais para colheita de material, e do envio das amostras devidamente acondicionadas para análise, o que pode não ser economicamente viável para todos os animais (Duff and Galyean, 2007).

Análises sanguíneas ou hematológicas podem indicar a gravidade da infecção assim como a sua natureza (bacteriana ou viral) (Radostits et al., 2002). Do sangue, é possível realizar testes quantitativos para análise como hormônios de estresse, proteínas de fase aguda e também anticorpos e antígenos presentes no animal (Flöck, 2004).

A análise laboratorial de exsudatos e secreções são o método mais comum utilizado em casos suspeitos de CRB (Radostits et al., 2002). Normalmente são realizados isolamentos virais, bacterianos ou fúngicos e antibiograma. No entanto, é necessário ter ciência que os organismos microbianos podem ser isolados nas diferentes regiões do trato respiratório, tanto em animais saudáveis quanto em animais doentes, sendo difícil a diferenciação entre os infectados e os animais hígidos (Allen et al., 1991). Para esse exame, é preferencial a seleção de animas na fase aguda do CRB e sem antibioticoterapia, uma vez que essa pode evitar ou diminuir o crescimento das culturas bacterianas no laboratório (Cooper and Brodersen, 2010). O material provindo destas coletas também pode ser submetido a exame citológico (Radostits et al., 2002). O aumento da temperatura, em conjunto com a leucocitose e com as alterações que ocorrem nas proteínas de fase aguda, é uma consequência da resposta sistêmica inicial do organismo à infecção ou à lesão tissular (Ceciliani et al., 2012). Assim, a utilização de ferramentas capazes de aferirem a temperatura pode ser utilizada como diagnóstico precoce de CRB. Dentre os dispositivos utilizados, pode ser citado temperatura retal e vaginal (Sharon et al., 2013), temperatura ruminal através de bolus intra ruminal (Timsit et al., 2011a, Timsit et al., 2011b) e da superfície externa do corpo através de termografia infravermelha (Schaefer et al., 2012).

Necropsia também oferece uma oportunidade para análise de amostras em laboratório de patologia para diagnóstico na identificação da doença ou encontrar os agentes patogênicos associados. Os achados de necropsia são de suma importância para tomada de decisões e recomendações futuras de gestão (Edwards, 2010)

\section{Tratamento para o CRB}

A aplicação de um tratamento eficaz para a afecção é fundamental para o controle da doença (Snowder et al., 2006, Timsit et al., 2011b). Após o tratamento, o tempo de recuperação é bastante variável e dependente de inúmeros fatores. Vale notar que os animais em que o CRB é detectado rapidamente e que são imediatamente submetidos a uma terapia antimicrobiana e anti-inflamatória, geralmente recuperam dentro de cinco a seis dias. Perante o GMD, esta estratégia seria o ideal, pois quanto menor for o período de tempo de recuperação, menores serão os efeitos da doença (Snowder et al., 2006). O registro de resposta ao tratamento, avaliação de necropsia de lesões (ou falta dela) é um método comprovado para determinar a precisão do diagnóstico e da falta de resposta terapêutica (Edwards, 2010).

\section{Prevenção e controle do complexo respiratório bovino}

Quando se aperfeiçoa o bem estar e a saúde dos animais, pode-se ter um aumento no incremento produtivo, aumentando o desempenho alimentar e, consequentemente, um maior peso de carcaça (Edwards, 2010). Quando se fala em período crítico para o CRB, é caracterizado a partir das duas primeiras semanas até um mês da permanência dos animais no confinamento, que está relacionado com o estresse do animal, desmame, transporte, alterações nutricionais, manejo pré e pós-entrada dos animais no confinamento (Bateman et al., 1990, Sowell et al., 1999, Snowder et al., 2006). Ao longo desse tempo, devem-se tomar atitudes de controle e medidas profiláticas para evitar a infecção dos animais por agentes patogênicos, fazendo $\mathrm{o}$ controle dos fatores predisponentes do CRB (Edwards, 2010).

Um programa profilático ideal deve ter como alicerce um programa de desmame eficiente assim como um esquema vacinal eficaz antes da transição para o confinamento. Nesse último item, além de ser necessária uma estimulação suplementar do sistema imune, é primordial que existam boas práticas de manejo e medidas sanitárias e terapêuticas eficientes (Fulton et al., 2002, Edwards, 2010). Todavia, é possível que ocorram surtos, devido ao sistema imune complexo, agente patogênico, ambiente e práticas de manejo (Edwards, 2010). 
Segundo Stokka (2010), e com base em estudos anteriores, a identificação dos fatores predisponentes associados à doença é de primordial importância para o controle efetivo. Conseguindo estabelecer os fatores predisponentes do CRB para determinar os pontos cruciais de controle, consegue-se organizar e aprimorar os procedimentos profiláticos e as boas práticas de manejo, com consequente amplificação da resposta imune (Edwards, 2010).

A prevenção e controle do CRB, de certa forma, é a redução da introdução, exposição e transmissão de agentes patogênicos no confinamento, sendo um dos principais objetivos da profilaxia, considerando que a erradicação total desses agentes não é possível. Todavia, a segregação de animais doentes e o controle sobre a população diminui a transmissão desses agentes entre os bovinos (Callan and Garry, 2002, Snowder et al., 2006, Edwards, 2010).

A biossegurança deve ser implementada com práticas de manejo rigorosas na sanitização e desinfecção do confinamento, além, é claro, de uma correta higienização dos cochos de alimentação e água. Os equipamentos utilizados para realizar essa limpeza devem ser higienizados e não poderão ser utilizados para outras funções. No mesmo sentido, o necrotério deve estar localizado o mais distante possível da criação (Edwards, 2010)

A ventilação e os sistemas de pulverizadores de água são grandes aliados na prevenção do $\mathrm{CRB}$, pois assessoram a remoção de partículas que podem ser patogênicas como agentes infecciosos, poeira e gases irritantes (Edwards, 2010). Facilitar a proteção dos animais contra as adversidades ambientais, assim como exercer boas práticas de manejo auxiliam os animais na defesa contra condições ambientais imunodepressoras. Tornar facultativa a proteção irá permitir a homeostase do animal em relação a sua temperatura corporal e umidade, usando de artifícios como sombras naturais ou artificiais (sombrites), sistemas pulverizadores de água, fontes adicionais de água e ventilação forçada ou manual para permitir quatro trocas de ar por hora e auxiliar no controle de partículas potencialmente patogênicas, mantendo um ambiente favorável e saudável para evitar o estresse pelo calor (Edwards, 2010).

Abrigos, camas de palha e quebra ventos são também essenciais para abrigar os animais do frio, evitando o estresse pelo frio, assim como se deve impedir o acúmulo de lama nas instalações
(Edwards, 2010).

Boas práticas de manejo que evitem assobios, vocalização elevada ou excessiva, bastões elétricos, excesso de animais nos currais, mas favoreçam manipulação dos animais de forma calma e por curto tempo poderá diminuir a resposta negativa do estresse (Grandin, 1997, Edwards, 2010).

Para se evitar deslizes e quedas dos animais, um bom piso deve ser feito, evitando-se o tratamento para as lesões musculoesqueléticas. $\mathrm{Na}$ entrada dos animais, nos locais onde se tem meses de inverno rigoroso, camas limpas devem estar preparadas, assim como o fornecimento de água limpa e tratada, alimentação balanceada e limpeza das instalações são imprescindíveis (Edwards, 2010).

A eficiência no aproveitamento dos alimentos é dependente do histórico nutricional, pois a qualidade do alimento fornecido antes da entrada no confinamento é influenciada em situações que induzem ao estresse do animal, pelo fato do desafio nutricional ser incorporado na alimentação diária dos estabelecimentos de engorda, gerando alterações de comportamento alimentar e nos parâmetros fisiológicos (Galyean and Hubbert 1995).

A formulação de uma dieta palatável adequada e equilibrada, assim como a administração de volumosos podem compensar carências nutricionais, evitando o desenvolvimento de algumas doenças metabólicas ou digestórias, que podem ser imunossupressoras, além de atrair o animal para o comedouro (Edwards, 2010). Aos animais que apresentarão a doença, pode-se fornecer uma dieta rica de proteínas, energia, vitaminas e sais minerais, incluindo zinco orgânico e cobre, pois esses animais podem ter uma diminuição acentuada na alimentação e ganho de peso (Sowell et al., 1999, Edwards, $\underline{2010)}$.

Para a prevenção, deve-se desenvolver o sistema imune do bezerro desde o seu nascimento juntamente com a mãe, e que esse desenvolvimento seja contínuo na cadeia de produção. Se o método for fazer um programa vacinal em um período crítico, a imunidade suficiente para superar a doença não irá ser eficiente. Existem diversos programas vacinais que aumentam o valor econômico dos bezerros em várias fases do seu desenvolvimento (Edwards, 2010). O seu ponto chave consiste na redução e 
controle dos surtos da CRB, diminuindo a susceptibilidade do animal e a transmissão de patógenos (Edwards, 2010, Stokka, 2010).

Há uma grande diversidade de vacinas únicas ou combinadas com antígenos modificados, mortos ou combinados, assim como há vacinas com combinações virais ou bacterianas. Nas virais, os antígenos que estão em maior presença são BHV-1, PIV-3, BRSV e o vírus da DVB. Os bacterianos mais comumente encontrados para as vacinas de CRB são Mannheimia haemolytica, Pasteurella multocida e Histophilus somni (Edwards, 2010). Vale ressaltar que embora exista um grande desenvolvimento na área das vacinas, apenas $75 \%$ dos animais vacinados são protegidos (Rice et al., 2007), já que a administração da vacina expõe o antígeno ao sistema imune, mas não garante que esse responda positivamente (Edwards, 2010).

De modo geral, faz-se necessário fazer a administração de duas doses de vacinas, com um intervalo de duas a quatro semanas entre elas, para que ocorra uma melhor produção de anticorpos e, consequentemente, da resposta imune. Duff and Galyean (2007) ainda dizem que se a vacinação não for feita no pré desmame, deve ser feita próxima do desmame com um reforço de 14 a 20 dias depois.

Uma vez que o sistema imunológico encontrase mais debilitado no período inicial do confinamento, há uma elevada probabilidade de que a primeira dose vacinal seja incapaz de fazer uma resposta imunológica eficaz, sendo que a repetição da dose da vacina deve ser feita, impreterivelmente, nos bezerros que são considerados de alto risco ou que estão debilitados, após três semanas (Edwards, 2010).

Diversos pesquisadores esclareceram a capacidade do uso da profilaxia de antimicrobianos para a redução da morbidade da $\mathrm{CRB}$, aumentando o desempenho dos bovinos no confinamento (Galyean and Hubbert, 1995, Vogel et al., 1998, Cusack et al., 2003). A via de administração pode ser parenteral ou oral, podendo ser através de alimentos ou água (Taylor et al., 2010). A via oral é uma técnica desafiadora, pois quando os animais estão doentes eles diminuem a ingestão de alimentos (Sowell et al., 1999). Sowell et al. (1999) afirmam que a medicação em massa pode ser mais eficiente quando aplicada quatro dias após a entrada dos animais no confinamento, sendo que esses irão se deslocar mais vezes nos cochos de alimentação e de água. Duff et al. (2000) retrocederam que os animais possuem um aumento do desempenho e uma diminuição da morbidade com o uso de clortetraciclina na alimentação.

A metafilaxia é a administração antimicrobiana terapêutica que é dada a todos os animais como forma de prevenção da doença, tendo como objetivo minimizar ou eliminar um surto da enfermidade, assumindo uma importância quando se fala de doença subclínica. A correta aplicação da metafilaxia consiste em aplicar em $10 \%$ dos animais a terapia antimicrobiana durante dois ou três dias consecutivos ou utilizar em mais de $25 \%$ dos animais em um único dia (Edwards, 2010).

A medicação em massa e a metafilaxia são usualmente usadas no período inicial do confinamento, pois nessa fase ocorre uma maior chance dos animais se infectarem com agentes patogênicos pelas situações estressantes. A utilização do fármaco deverá ser cuidadosa devido a resistência antimicrobiana (Duff and Galyean, 2007). Para minimizar o uso de antimicrobianos nos confinamentos, têm sido aplicadas outras estratégias, como a aplicação de antimicrobianos em bezerros considerados de alto risco, sendo considerado um método de prevenção e controle eficaz (Vogel et al., 1998, Edwards, 2010, González-Martín et al., 2011).

\section{Conclusão}

Devido ao CRB ser uma doença multifatorial, de difícil precisão no diagnóstico e dispendioso com tratamentos muitas vezes ineficazes e caros, é de suma importância o conhecimento e a atualização do profissional responsável pela sanidade, nutrição e manejo dos bovinos a serem trabalhados para reduzir prejuízos e perdas produtivas que podem ser causados por essa enfermidade. $\mathrm{O}$ diagnóstico precoce é importante para o reconhecimento e mais precisa é tomada de decisão para o que foi constatado nos testes realizados para tal afecção.

\section{Referências Bibliográficas}

Allen, J. W., Viel, L., Bateman, K. G., Rosendal, S., Shewen, P. E. \& Physick-Sheard, P. 1991. The microbial flora of the respiratory tract in feedlot calves: associations between nasopharyngeal and bronchoalveolar lavage cultures. Canadian Journal of Veterinary Research, 55, 341.

Apley, M. 2006. Bovine respiratory disease: pathogenesis, clinical signs, and treatment in 
lightweight calves. Veterinary Clinics of North America: Food Animal Practice, 22, 399-411.

Baker, J. C. \& Frey, M. L. 1985. Bovine respiratory syncytial virus. The Veterinary Clinics of North America. Food Animal Practice, 1, 259-275.

Bateman, K. G., Martin, S. W., Shewen, P. E. \& Menzies, P. I. 1990. An evaluation of antimicrobial therapy for undifferentiated bovine respiratory disease. The Canadian Veterinary Journal, 31, 689.

Baule, C., Kulcsar, G., Belak, K., Albert, M., Mittelholzer, C., Soos, T., Kucsera, L. \& Belak, S. 2001. Pathogenesis of primary respiratory disease induced by isolates from a new genetic cluster of bovine viral diarrhea virus type I. Journal of Clinical Microbiology, $39,146-153$.

Booker, C. W., Guichon, P. T., Jim, G. K., Schunicht, O. C., Harland, R. J. \& Morley, P. S. 1999. Seroepidemiology of undifferentiated fever in feedlot calves in western Canada. The Canadian Veterinary Journal, 39-48, 40.

Boyce, J. D. \& Adler, B. 2000. The capsule is a virulence determinant in the pathogenesis of Pasteurella multocida M1404 (B: 2). Infection and Immunity, 68, 3463-3468.

Callan, R. J. \& Garry, F. B. 2002. Biosecurity and bovine respiratory disease. Veterinary Clinics of North America: Food Animal Practice, 18, 57-77.

Carroll, J. A. \& Forsberg, N. E. 2007. Influence of stress and nutrition on cattle immunity. Veterinary Clinics of North America: Food Animal Practice, 23, 105-149.

Ceciliani, F., Ceron, J. J., Eckersall, P. D. \& Sauerwein, H. 2012. Acute phase proteins in ruminants. Journal of Proteomics, 75, 42074231.

Cooper, V. L. \& Brodersen, B. W. 2010. Respiratory disease diagnostics of cattle. Veterinary Clinics of North America: Food Animal Practice, 26, 409-416.

Cusack, P. M. V., McMeniman, N. P. \& Lean, I. J. 2003. The medicine and epidemiology of bovine respiratory disease in feedlots. Australian Veterinary Journal, 81, 480-487.

Cusack, P. M. V., McMeniman, N. P. \& Lean, I. J. 2007. Feedlot entry characteristics and climate: their relationship with cattle growth rate, bovine respiratory disease and mortality. Australian Veterinary Journal, 85, 311-316.

Dabo, S. M., Taylor, J. D. \& Confer, A. W. 2007. Pasteurella multocida and bovine respiratory disease. Animal Health Research Reviews, 8, 129-150.

Duff, G. C. \& Galyean, M. L. 2007. Board-invited review: Recent advances in management of highly stressed, newly received feedlot cattle. Journal of Animal Science, 85, 823-840.

Duff, G. C., Walker, D. A., Malcolm-Callis, K. J., Wiseman, M. W. \& Hallford, D. M. 2000. Effects of preshipping vs. arrival medication with tilmicosin phosphate and feeding chlortetracycline on health and performance of newly received beef cattle. Journal of Animal Science, 78, 267-274.

Edwards, T. A. 2010. Control methods for bovine respiratory disease for feedlot cattle. Veterinary Clinics of North America: Food Animal Practice, 26, 273-284.

Flöck, M. 2004. Diagnostic ultrasonography in cattle with thoracic disease. The Veterinary Journal, 167, 272-280.

Fulton, R. W. \& Confer, A. W. 2012. Laboratory test descriptions for bovine respiratory disease diagnosis and their strengths and weaknesses: gold standards for diagnosis, do they exist? The Canadian Veterinary Journal, 53, 754.

Fulton, R. W., Cook, B. J., Step, D. L., Confer, A. W., Saliki, J. T., Payton, M. E., Burge, L. J., Welsh, R. D. \& Blood, K. S. 2002. Evaluation of health status of calves and the impact on feedlot performance: assessment of a retained ownership program for postweaning calves. Canadian Journal of Veterinary Research, 66, 173-180.

Galyean, M. L. \& Hubbert, M. E. 1995. Effects of season, health, and management on feed intake by beef cattle. In: Oewns, F. N. (ed.) Symposium: Intake by Feedlot Cattle. Oklahoma.

Ganaba, R., Belanger, D., Dea, S. \& BigrasPoulin, M. 1995. A seroepidemiological study of the importance in cow-calf pairs of respiratory and enteric viruses in beef operations from northwestern Quebec. Canadian Journal of Veterinary Research, 59, 26.

González-Martín, J. V., Elvira, L., López, M. C., 
Villalobos, N. P., López-Guerrero, E. C. \& Astiz, S. 2011. Reducing antibiotic use: Selective metaphylaxis with florfenicol in commercial feedlots. Livestock Science, 141, 173-181.

Grandin, T. 1997. Assessment of stress during handling and transport. Journal of Animal Science, 75, 249-57.

Griffin, D., Chengappa, M. M., Kuszak, J. \& McVey, D. S. 2010. Bacterial pathogens of the bovine respiratory disease complex. Veterinary Clinics of North America: Food Animal Practice, 26, 381-394.

Hay, K. E., Ambrose, R. C. K., Morton, J. M., Horwood, P. F., Gravel, J. L., Waldron, S., Commins, M. A., Fowler, E. V., Clements, A. C. A. \& Barnes, T. S. 2016a. Effects of exposure to Bovine viral diarrhoea virus 1 on risk of bovine respiratory disease in Australian feedlot cattle. Preventive Veterinary Medicine, 126, 159-169.

Hay, K. E., Barnes, T. S., Morton, J. M., Gravel, J. L., Commins, M. A., Horwood, P. F., Ambrose, R. C., Clements, A. C. A. \& Mahony, T. J. 2016b. Associations between exposure to viruses and bovine respiratory disease in Australian feedlot cattle. Preventive Veterinary Medicine, 127, 121-133.

Lillie, L. E. \& Thomson, R. G. 1972. The pulmonary clearance of bacteria by calves and mice. Canadian Journal of Comparative Medicine, 36, 129-137.

Martin, S. W. \& Bohac, J. G. 1986. The association between serological titers in infectious bovine rhinotracheitis virus, bovine virus diarrhea virus, parainfluenza-3 virus, respiratory syncytial virus and treatment for respiratory disease in Ontario feedlot calves. Canadian Journal of Veterinary Research, 50, 351-358.

Prado, M. E., Prado, T. M., Payton, M. \& Confer, A. W. 2006. Maternally and naturally acquired antibodies to Mannheimia haemolytica and Pasteurella multocida in beef calves. Veterinary Immunology and Immunopathology, 111, 301-307.

Radostits, O. M., Gay, C. C., Blood, D. C., Hinchcliff, K. W. \& McKenzie, R. 2002. Clínica Veterinária: um tratado de doenças dos bovinos, ovinos, suínos, caprinos $e$ eqüinos. Guanabara Koogan, Rio de Janeiro.
Rice, J. A., Carrasco-Medina, L., Hodgins, D. C. \& Shewen, P. E. 2007. Mannheimia haemolytica and bovine respiratory disease. Animal Health Research Reviews, 8, 117-128.

Roth, J. A., Kaeberle, M. L. \& Griffith, R. W. 1981. Effects of bovine viral diarrhea virus infection on bovine polymorphonuclear leukocyte function. American Journal of Veterinary Research, 42, 244-250.

Sanderson, M. W., Dargatz, D. A. \& Wagner, B. A. 2008. Risk factors for initial respiratory disease in United States' feedlots based on producer-collected daily morbidity counts. Canadian Veterinary Journal, 49, 373-378.

Schaefer, A. L., Cook, N. J., Bench, C., Chabot, J. B., Colyn, J., Liu, T., Okine, E. K., Stewart, M. \& Webster, J. R. 2012. The non-invasive and automated detection of bovine respiratory disease onset in receiver calves using infrared thermography. Research in Veterinary Science, 93, 928-935.

Sharon, K. P., Duff, G. C., Paterson, J. A., Dailey, J. W., Carroll, J. A. \& Marceau, E. A. 2013. Case study: Effects of timing of a modifiedlive respiratory viral vaccination on performance, feed intake, antibody titer response, and febrile response of beef heifers. The Professional Animal Scientist, 29, 307312.

Snowder, G. D., Van Vleck, L. D., Cundiff, L. V. \& Bennett, G. L. 2005. Influence of breed, heterozygosity, and disease incidence on estimates of variance components of respiratory disease in preweaned beef calves. Journal of Animal Science, 83, 1247-1261.

Snowder, G. D., Van Vleck, L. D., Cundiff, L. V. \& Bennett, G. L. 2006. Bovine respiratory disease in feedlot cattle: environmental, genetic, and economic factors. Journal of Animal Science, 84, 1999-2008.

Sowell, B. F., Branine, M. E., Bowman, J. G., Hubbert, M. E., Sherwood, H. E. \& Quimby, W. 1999. Feeding and watering behavior of healthy and morbid steers in a commercial feedlot. Journal of Animal Science, 77, 11051112.

Srikumaran, S., Kelling, C. L. \& Ambagala, A. 2007. Immune evasion by pathogens of bovine respiratory disease complex. Animal Health Research Reviews, 8, 215-229.

Step, D., Krehbiel, C., DePra, H., Cranston, J., 
Fulton, R., Kirkpatrick, J., Gill, D., Payton, M., Montelongo, M. \& Confer, A. 2008. Effects of commingling beef calves from different sources and weaning protocols during a fortytwo-day receiving period on performance and bovine respiratory disease. Journal of Animal Science, 86, 3146-3158.

Stokka, G. L. 2010. Prevention of respiratory disease in cow/calf operations. Veterinary Clinics of North America: Food Animal Practice, 26, 229-241.

Taylor, J. D., Fulton, R. W., Lehenbauer, T. W., Step, D. L. \& Confer, A. W. 2010. The epidemiology of bovine respiratory disease: what is the evidence for preventive measures. Canadian Veterinary Journal, 51, 1351-9.

Timsit, E., Assié, S., Quiniou, R., Seegers, H. \& Bareille, N. 2011a. Early detection of bovine respiratory disease in young bulls using reticulo-rumen temperature boluses. The Veterinary Journal, 190, 136-142.

Timsit, E., Bareille, N., Seegers, H., Lehebel, A. \& Assie, S. 2011b. Visually undetected fever episodes in newly received beef bulls at a fattening operation: occurrence, duration, and impact on performance. Journal of Animal Science, 89, 4272-4280.

Townsend, H. G., Meek, A. H., Lesnick, T. G. \& Janzen, E. D. 1989. Factors associated with average daily gain, fever and lameness in beef bulls at the Saskatchewan Central Feed Test Station. Canadian Journal of Veterinary
Research, 53, 349-354.

Vogel, G. J., Laudert, S. B., Zimmermann, A., Guthrie, C. A., Mechor, G. D. \& Moore, G. M. 1998. Effects of tilmicosin on acute undifferentiated respiratory tract disease in newly arrived feedlot cattle. Journal of the American Veterinary Medical Association, 212, 1919-1924.

Wittum, T. E. \& Perino, L. J. 1995. Passive immune status at postpartum hour 24 and longterm health and performance of calves. American Journal of Veterinary Research, 56, 1149-1154.

Wittum, T. E., Woollen, N. E., Perino, L. J. \& Littledike, E. T. 1996. Relationships among treatment for respiratory tract disease, pulmonary lesions evident at slaughter, and rate of weight gain in feedlot cattle. Journal of the American Veterinary Medical Association, 209, 814-818.

\section{Article History:}

Received 19 December 2016

Accepted 21 January 2017

Available on line 16 March 2017

License information: This is an open-access article distributed under the terms of the Creative Commons Attribution License 4.0, which permits unrestricted use, distribution, and reproduction in any medium, provided the original work is properly cited. 